\title{
Performance of Concrete Made with Different Coarse Aggregate Particle Sizes under Sulfate Solution
}

\author{
Trong-Phuoc Huynh ${ }^{1 *}$, Si-Huy Ngo ${ }^{2}$, Chao-Lung Hwang ${ }^{3}$ \\ ${ }^{1}$ Department of Rural Technology, College of Rural Development, Can Tho University, Can Tho City, Vietnam. \\ 2 Department of Engineering and Technology, Hong Duc University, Thanh Hoa City, Vietnam. \\ 3 Department of Civil and Construction Engineering, National Taiwan University of Science and Technology, \\ Taipei City, Taiwan.
}

* Corresponding author. Tel.: (+84)985191377; email: htphuoc@ctu.edu.vn Manuscript submitted September 10, 2017; accepted November 24, 2017. doi: 10.17706/ijmse.2017.5.4.140-144

\begin{abstract}
This paper presents the result of an investigation on the performance of concrete produced with different coarse aggregate sizes (CAS) and fully immersed in 5\% sodium sulfate solution. Concrete mixtures were prepared with two water-to-binder ratios of 0.35 and 0.45 using four different maximum particle sizes $\left(D_{\max }\right)$ of coarse aggregates $(9.5 \mathrm{~mm}, 12.5 \mathrm{~mm}, 19 \mathrm{~mm}$, and $25 \mathrm{~mm})$. Test results indicate that the workability of concrete increases with increasing the CAS. Concrete made with $D_{\max }$ of $12.5 \mathrm{~mm}$ shows the highest compressive strength, whereas concrete made with $\mathrm{D}_{\max }$ of $25 \mathrm{~mm}$ shows the lowest compressive strength. In addition, the compressive strength of concrete immersed in sulfate solution reduces around 8-13\% in comparison with that of concrete cured in water. Moreover, all of the concrete samples perform good durability with ultrasonic pulse velocity values of all greater than $4200 \mathrm{~m} / \mathrm{s}$.
\end{abstract}

Key words: Concrete, coarse aggregate size, sulfate solution, compressive strength, workability, ultrasonic pulse velocity.

\section{Introduction}

Concrete is a mixture of binder materials, fine aggregate, coarse aggregate, water, and admixtures. Therefore, properties of concrete are strongly depended on the ingredients of concrete and their quality. In which, the coarse aggregate is an important factor, especially the coarse aggregate size (CAS). Thus, ACI 211.1-91 [1] selects the mix proportions of concrete based on the maximum CAS. However, the findings from previous studies regarding the effect of CAS on properties of concrete had a large difference. Some researchers concluded that the compressive strength of concrete increased with reducing the CAS [2]-[7], while the others reported that the compressive strength of concrete increased with increasing the CAS [8], [9]. Furthermore, Rathish and Krishna [10] indicated that concrete reached the highest compressive strength with the use of optimal CAS. This finding was found based on the investigation of concrete made with the CAS of $8 \mathrm{~mm}, 12.5 \mathrm{~mm}, 16 \mathrm{~mm}$, and $20 \mathrm{~mm}$. The optimal CAS found in the study was $12.5 \mathrm{~mm}$. On the other hand, some studies showed that workability of concrete reduced when the CAS decreased [2], [4], [7], whereas Rathish and Krishna's experimental work exhibited that the workability of concrete increased with decreasing the CAS [10]. All previous studies related to CAS were conducted in normal condition. The effect of CAS on the properties of concrete fully immersed in sulfate solution is still unknown. Thus, the primary objective of the present study is to investigate the performance of concrete made with different 
CAS under sulfate solution. The reduction in compressive strength of concrete immersed in sulfate solution compared with that of concrete cured in water was also evaluated.

\section{Materials and Experimental Works}

\subsection{Materials Properties and Mixture Proportions}

Binder materials used in this study were cement and fly ash that provided by local companies in Thanh Hoa province, Vietnam. The cement used was Nghi Son type-PC40 with a specific gravity of 3.12. The fly ash used was classified as class-F with a specific gravity of 2.16. The chemical compositions of cement and fly ash are shown in Table 1. The natural river sand with fineness modulus of 2.87 , density of $2.62 \mathrm{~T} / \mathrm{m}^{3}$, dry rodded weight of $1.50 \mathrm{~T} / \mathrm{m}^{3}$, moisture content of $4.35 \%$, and water absorption capacity of $1.08 \%$ was used as fine aggregate. Crushed stone with density of $2.69 \mathrm{~T} / \mathrm{m}^{3}$, dry rodded weight of $1.39 \mathrm{~T} / \mathrm{m}^{3}$, moisture content of $0.25 \%$, and water absorption capacity of $0.08 \%$ was used as coarse aggregate. The superplasticizer with a specific gravity of 1.15 was used with a dosage of $1 \%$ by total amount of binder materials.

All concrete mixtures were designed in compliance with ACI 211.1-91 [1] as shown in Table 2. Two group mixtures were designed with water-to-binder ratios of 0.35 and 0.45 , referred to M35 and M45, respectively. Each group consisted of four mixtures, which were made with different maximum CASs of $9.5 \mathrm{~mm}, 12.5 \mathrm{~mm}$, $19 \mathrm{~mm}$, and $25 \mathrm{~mm}$.

Table 1. Chemical Compositions of Cement and Fly Ash

\begin{tabular}{ccccccccccc}
\hline $\begin{array}{c}\text { Compositions } \\
\text { (wt. \%) }\end{array}$ & $\mathrm{SiO}_{2}$ & $\mathrm{Al}_{2} \mathrm{O}_{3}$ & $\mathrm{Fe}_{2} \mathrm{O}_{3}$ & $\mathrm{CaO}$ & $\mathrm{MgO}$ & $\mathrm{SO}_{3}$ & $\mathrm{~K}_{2} \mathrm{O}$ & $\mathrm{Na}_{2} \mathrm{O}$ & Others & $\begin{array}{c}\text { Loss on } \\
\text { ignition (\%) }\end{array}$ \\
\hline Cement & 22.4 & 5.3 & 4.0 & 55.9 & 2.8 & 2.1 & 0.8 & 0.3 & 4.5 & 1.9 \\
Fly ash & 48.4 & 20.4 & 4.8 & 2.8 & 1.4 & 0.2 & 1.1 & 0.8 & 4.3 & 15.8 \\
\hline
\end{tabular}

Table 2. Mix Proportions for the Preparation of Concrete Samples

\begin{tabular}{cccccccc}
\hline \multirow{2}{*}{ Group } & \multirow{2}{*}{ w/b } & \multicolumn{7}{c}{ Concrete ingredients proportion $\left(\mathrm{kg} / \mathrm{m}^{3}\right)$} \\
\cline { 4 - 8 } & & Cement & Fly ash & Sand & Stone & Water & SP \\
\hline M35 & 0.35 & 469.1 & 52.1 & 811.6 & 898.4 & 172.2 & 5.2 \\
M45 & 0.45 & 365.4 & 40.6 & 910.3 & 899.7 & 178.7 & 4.1 \\
\hline
\end{tabular}

\subsection{Samples preparation and test methods}

Workability and fresh unit weight of all mixtures were measured right after mixing. Then, concrete samples were prepared in cylinders with a diameter of $10 \mathrm{~cm}$ and a height of $20 \mathrm{~cm}$. After one day, all samples were de-molded and fully immersed in $5 \% \mathrm{Na}_{2} \mathrm{SO}_{4}$ solution until the testing days. The compressive strength and ultrasonic pulse velocity tests were conducted at $3,7,14,28,56$, and 91 days. The average value of three concrete samples at each testing age was reported.

\section{Results and Discussion}

\subsection{Properties of Fresh Concrete}

Table 3 shows the slump and fresh unit weight of all concrete mixtures. Concretes made with $\mathrm{D}_{\max }$ of 9.5 $\mathrm{mm}$ and $12.5 \mathrm{~mm}$ showed a slightly higher unit weight than two others made with $\mathrm{D}_{\max }$ of $19 \mathrm{~mm}$ and 25 $\mathrm{mm}$. It may be due to the arrangement of coarse aggregate particles inner concrete structure. The large coarse aggregate particles easily create larger pores than the small coarse aggregate particles. These large pores are more difficult to fully fill by paste. However, the difference of unit weight between the concrete mixtures is insignificant.

The slump of the concrete mixture increased with increasing $D_{\max }$ of coarse aggregate. This finding is similar to previous studies [2], [4], [7]. The larger CAS is associated with less surface area [11] and thus required less amount of water for wetting and of paste for lubricating the surface of coarse aggregates. For 
the same quantity of water, the amount of water on the surface of large CAS is more than that on the surface of small CAS, thus increasing the workability of concrete.

Table 3. Properties of Fresh Concrete Mixtures

\begin{tabular}{cccccc}
\hline Mixture ID. & $\mathrm{w} / \mathrm{b}$ & SP dosage $\left(\mathrm{kg} / \mathrm{m}^{3}\right)$ & FA content $(\%)$ & Slump $(\mathrm{mm})$ & Fresh unit weight $\left(\mathrm{kg} / \mathrm{m}^{3}\right)$ \\
\hline 35-9.5 & & & & 16 & 2523 \\
M35-12.5 & \multirow{2}{*}{0.35} & \multirow{2}{*}{5.2} & 10 & 36 & 2523 \\
M35-19 & & & & 55 & 2513 \\
M35-25 & & & & 61 & 2517 \\
\hline M45-9.5 & & \multirow{2}{*}{4.1} & & 39 & 2514 \\
M45-12.5 & 0.45 & & & 85 & 2513 \\
M45-19 & & & 112 & 2493 \\
M45-25 & & & & 105 \\
\hline
\end{tabular}

\subsection{Compressive Strength Development}

Figs. 1(a) and 1(b) show the compressive strength development of the M35 and M45 mixtures, respectively. All of the concrete mixtures exhibited an increase of compressive strength during the time. The M35 mixtures had a higher compressive strength than the corresponding M45 mixtures. It is due to the water-to-binder ratio of M35 mixtures is lower than that of M45 mixtures. From Fig. 1, concrete samples made with $D_{\max }$ of $12.5 \mathrm{~mm}$ showed the highest compressive strength, followed by concrete samples made with $\mathrm{D}_{\max }$ of $9.5 \mathrm{~mm}, 19 \mathrm{~mm}$, and then $25 \mathrm{~mm}$. This finding is similar to Rathish and Krishna' experimental result [10]. It means that the compressive strength of concrete reached the highest value with the use of optimal CAS. In this case, optimal $\mathrm{D}_{\max }$ is close to $12.5 \mathrm{~mm}$. The compressive strength of concrete made with $\mathrm{D}_{\max }$ of $25 \mathrm{~mm}$ was lowest. Hence, concrete made with larger CAS had lower compressive strength than concrete made with smaller CAS. However, the concrete made with $D_{\max }$ of $12.5 \mathrm{~mm}$ showed a higher compressive strength than concrete made with $\mathrm{D}_{\max }$ of $9.5 \mathrm{~mm}$. It is attributable to the bond between coarse aggregates. For coarse aggregate with $D_{\max }$ of $9.5 \mathrm{~mm}$, the particle sizes are small; therefore, the interlocking and bond among coarse aggregates is weaker than coarse aggregate with $\mathrm{D}_{\max }$ of $12.5 \mathrm{~mm}$. This finding indicated that CAS strongly affects the compressive strength of concrete both under normal condition and sulfate attack condition. It is related to internal bleeding, the development of microcracks, and bonds among coarse aggregate particles [11].

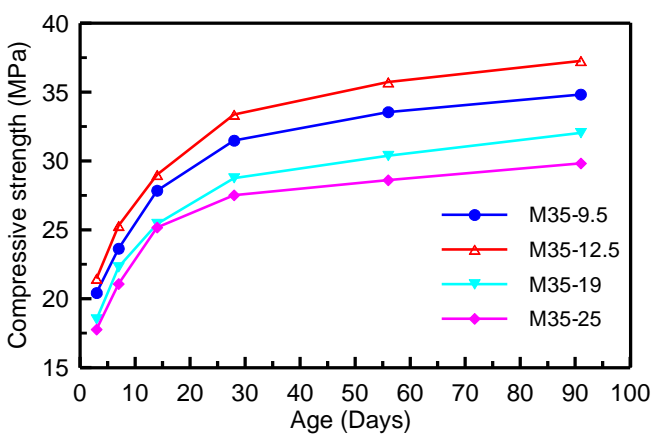

(a)

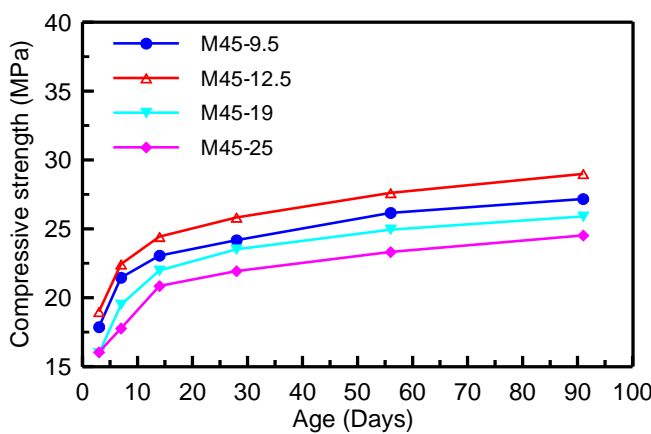

(b)

Fig. 1. Compressive strength development of (a) M35 mixtures and (b) M45 mixtures.

\subsection{Relative Compressive Strength}

Fig. 2 shows the ratio of the compressive strength of concrete fully immersed in sulfate solution and concrete cured in water. For the M35 group, all concrete mixtures showed a similar reduction rate. For the M45 group, concrete made with $\mathrm{D}_{\max }$ of $12.5 \mathrm{~mm}$ exhibited the least reduction in compressive strength, 
followed by concrete made with $D_{\max }$ of $9.5 \mathrm{~mm}, 19 \mathrm{~mm}$, and then $25 \mathrm{~mm}$. At early state, concrete under sulfate solution had a little higher compressive strength than that under water. It is attributable to the formation of ettringite and gypsum, leading to a denser concrete structure. However, the 91-day compressive strength of concrete in sulfate solution reduced around 8-13\% compared with that of concrete cured in water. This result is related to the expansion of ettringite and gypsum at long-term causes the formation of micro-cracks inside the concrete, leading to a reduction in concrete strength.

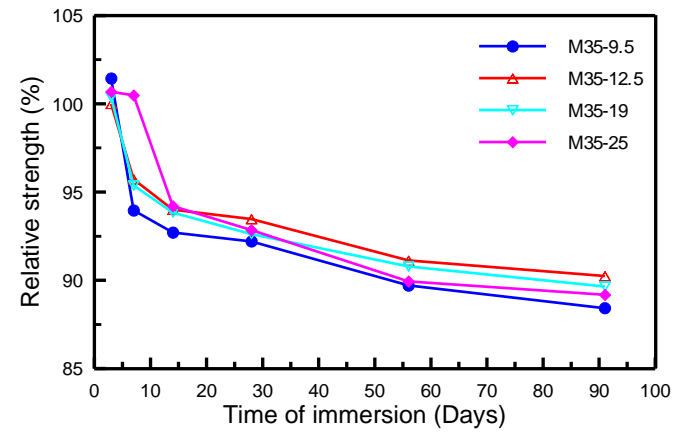

(a)

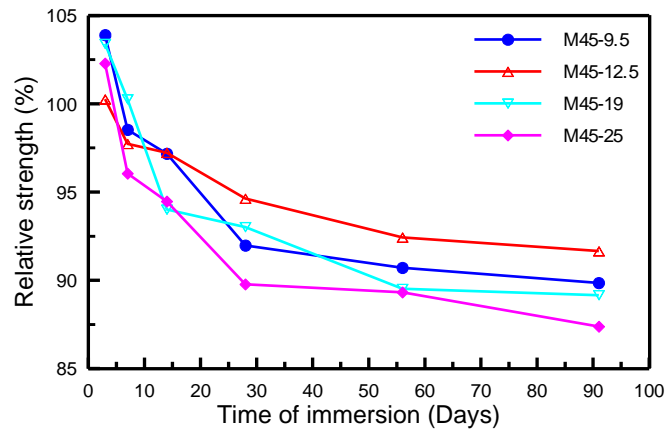

(b)

Fig. 2. Relative compressive strength of (a) M35 mixtures and (b) M45 mixtures under sulfate solution and water curing.

\subsection{Ultrasonic Pulse Velocity}

To assess the durability of concrete, the ultrasonic pulse velocity (UPV) was conducted with the test results are presented in Fig. 3. Generally, the M35 mixtures had higher UPV values than that of the corresponding M45 mixtures. It is due to the low water-to-binder ratio of M35 mixtures compared with M45 mixtures. In both groups, concretes made with $\mathrm{D}_{\max }$ of $12.5 \mathrm{~mm}$ showed the highest UPV values, followed by concretes made with $\mathrm{D}_{\max }$ of $9.5 \mathrm{~mm}, 19 \mathrm{~mm}$, and $25 \mathrm{~mm}$. This finding is in good agreement with a compressive strength of concrete. It also reflects the presence of voids, cracks, and density inner concrete structure. It also means that the CAS has a significant effect on the durable properties of concrete. However, all concrete samples prepared in this study had a UPV value of greater than $4200 \mathrm{~m} / \mathrm{s}$, which was classified as very good quality [12].

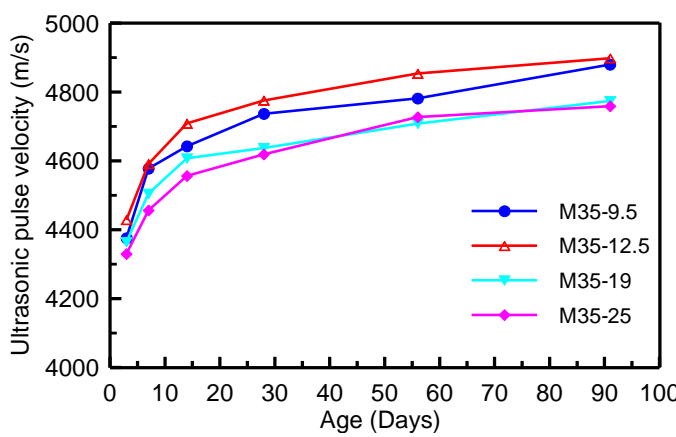

(a)

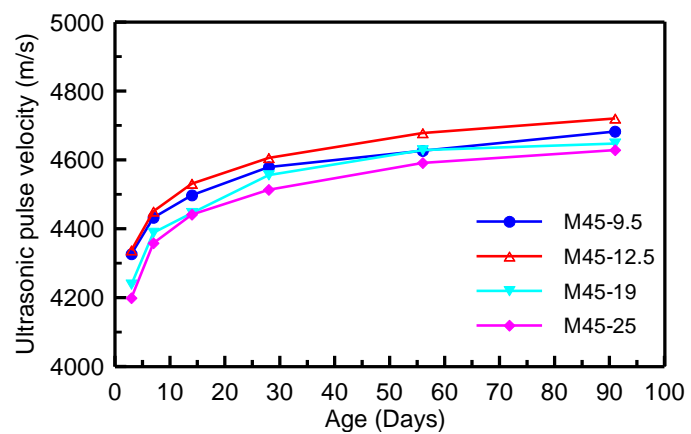

(b)

Fig. 3. UPV values of (a) M35 mixtures and (b) M45 mixtures.

\section{Conclusions}

This study investigates the performance of concrete produced using different CAS and fully immersed in 5\% $\mathrm{Na}_{2} \mathrm{SO}_{4}$ solution. Some major findings of the study are summarized as follows: 
1. The workability of fresh concrete increased with increasing the maximum CAS.

2. Concrete made with $D_{\max }$ of $12.5 \mathrm{~mm}$ showed the highest compressive strength, followed by concrete made with $D_{\max }$ of $9.5 \mathrm{~mm}, 19 \mathrm{~mm}$ and $25 \mathrm{~mm}$.

3. After 91 days of fully immersing in sulfate solution, the compressive strength of concrete samples reduced around $8-13 \%$ as compared with concrete samples cured in water.

4. All of the concrete samples prepared for this study showed the very good quality with the UPV values of all above $4200 \mathrm{~m} / \mathrm{s}$.

5. The CAS had a strong effect on the properties of concrete under sulfate solution rather than of the concrete cured in water.

\section{References}

[1] ACI Committee 211. (1991). Standard Practice for Selecting Proportions for Normal, Heavyweight, and Mass Concrete.

[2] Su, R. K. L., \& Bei, C. A. (2008). The effect of coarse aggregate size on the stress-strain curves of concrete under uniaxial compression. The Hong Kong Institution of Engineers Transaction, 15(3), 33-39.

[3] Grabiec, A. M., Zawal, D., \& Szulc, J. (2015). Influence of type and maximum aggregate size on some properties of high-strength concrete made of pozzolana cement in respect of binder and carbon dioxide intensity indexes. Construction and Building Materials, 98, 17-24.

[4] Woode, A., Amoah, D. K., Aguba, I. A., \& Ballow, P. (2015). The effect of maximum coarse aggregate size on the compressive strength of concrete produced in Ghana. Civil and Environmental Research, 7, 7-12.

[5] Yaşa, E., Erdoğan, Y., \& Kiliç, A. (2004). Effect of limestone aggregate type and water-cement ratio on concrete strength. Materials Letters, 58, 772-777.

[6] Yaqub, M., \& Bukhari, I. (2006). Effect of size of coarse aggregate on compressive strength of high strength concrete. Proceedings of the 31st Conference on our world in concrete \& structures. Singapore.

[7] Xie, W., Jin, Y., \& Li, S. (2012). Experimental research on the influence of grain size of coarse aggregate on pebble concrete compressive strength. Applied Mechanics and Materials, 238, 133-137.

[8] Kozul, R., \& Darwin, D. (1997). Effects of Aggregate Type, Size, and Content on Concrete Strength and Fracture Energy. (Report No. 43). Kansas: University of Kansas Center for Research, Inc., Lawrence.

[9] Meddah, M. S., Zitouni, S., \& Belâabes, S. (2010). Effect of content and particle size distribution of coarse aggregate on the compressive strength of concrete. Construction and Building Materials, 24, 505-512.

[10] Rathish, K. P., \& Krishna, R. M. V. (2012). A study on the effect of size of aggregate on the strength and sorptivity characteristics of cinder based light weight concrete. Research Journal of Engineering Sciences, 1(6), 27-35.

[11] Shetty, M. S. (2005). Concrete Technology Theory and Practice. New Delhi, India: S. Chand \& Company LTD.

[12] Carcano, R. S., \& Moreno, E. I. (2008). Evaluation of concrete made with crushed limestone aggregate based on ultrasonic pulse velocity. Construction and Building Materials, 22, 1225-1231.

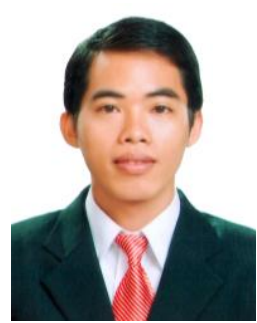

Trong-Phuoc Huynh is currently a lecturer of the Department of Rural Technology, College of Rural Development, Can Tho University, Can Tho City, Vietnam. He received his MSc. (2013) and Ph.D. degrees (2016) in Civil and Construction Engineering from National Taiwan University of Science and Technology, Taipei City, Taiwan. His research interests are in concrete science and technology, green construction materials, alkali-activated materials, controlled-low strength material, application of pozzolanic materials, and turning wastes into construction materials. 